\title{
Carotid Body Tumour as an Unusual Cardiovascular Pathology: Report of Two Cases
}

\author{
Hakan Atalay1, Atakan Atalay², Omer Faruk Dogan ${ }^{*}$ \\ ${ }^{1}$ Department of Cardiovascular Surgery, The Private Mersin Meadle-East Hospital, Mersin, Turkey \\ ${ }^{2}$ Department of Cardiovascular Surgery, Cukurova University Medical Faculty, Adana, Turkey \\ ${ }^{3}$ Department of Cardiovascular Surgery, Adana Numune Education and Training Hospital, Adana, Turkey \\ Email: ${ }^{*}$ ofdogan@hacettepe.edu.tr
}

Received 5 August 2014; revised 26 September 2014; accepted 27 October 2014

Copyright (C) 2014 by authors and OALib.

This work is licensed under the Creative Commons Attribution International License (CC BY).

http://creativecommons.org/licenses/by/4.0/

(c) (i) Open Access

\section{Abstract}

A carotid body tumour (CBT) is a rare form of an extra-adrenal pheochromocytoma. They are commonly diagnosed as asymptomatic neck masses. A careful preoperative evaluation is required to find out the functional and vascular status of these tumours. Herein, we report two cases of carotid body paraganglioma, their evaluation and surgical management.

\section{Keywords}

Carotid Body Tumour, Paraganglioma, Phaeochromocytoma

Subject Areas: Pathology, Surgery \& Surgical Specialties

\section{Introduction}

Paraganglioma (PGL) is a rare tumour of the head and neck, which arises from the neural crest cells [1]. Histopathologically similar to the adrenal gland neoplasm, it is usually benign and non-functional. In general, paraganglioma expands metastasis slowly and rarely [2] [3]. Because the paraganglionic cells contain very small amounts of catecholamines, significant catecholamine release is rarely seen. The medical therapy for a hormone producing paraganglioma should be addressed. For the treatment strategy of PGL, we started alpha blocker, and an additional fluid and a beta-blocker afterwards. We continue medication during surgery, and stop it after surgical intervention. Herein, we present our 2 cases with carotid body tumour which are diagnosed incidentally and surgical experiences.

${ }^{*}$ Corresponding author.

How to cite this paper: Atalay, H., Atalay, A. and Dogan, O.F. (2014) Carotid Body Tumour as an Unusual Cardiovascular Pathology: Report of Two Cases. Open Access Library Journal, 1: e1005. http://dx.doi.org/10.4236/oalib.1101005 


\section{Case Reports}

\subsection{Case 1}

A 37-year-old non-diabetic, hypertensive man presented with hoarseness of voice and left-sided ptosis of 1 year duration. He had a swelling in the angle of the right jaw, which had progressively been increasing in size over the past 14 years. A family history of PGL was negative. On examination, there was a $5 \mathrm{~cm} \times 4 \mathrm{~cm}$ pulsatile mass in the upper third of the left sternocleidomastoid, which was mobile laterally without an audible bruit. Right-sided Horner's syndrome was present. Doppler ultrasonography showed a highly vascular mass at the bifurcation of the common carotid artery. Magnetic resonance (MR) imaging showed a $5 \mathrm{~cm} \times 4 \mathrm{~cm} \times 3 \mathrm{~cm}$ mass in the left carotid space, with intense enhancement on T2-weighted images suggestive of a CBT. A preoperative angiogram was done to see the vascularity of the tumor. Tumor blush and splaying the carotid bifurcation was seen in this patient. 24-hour urinary metanephrines (MN) and vanillylmandelic acid (VMA) were elevated andI meta-iodobenzylguanidine (I-MIBG) scintigraphy showed uptake at the tumour site. The patient underwent successful surgical resection of the tumour (Figure 1 and Figure 2) after preoperative alpha blockade for 10 days. Postoperatively, he recovered from Horner's syndrome, showed improvement in hoarseness and is followed-up annually with urinary MN and MR imaging of the tumour bed. Histopathologic examination showed that firm, rubbery well-encapsulated masses composed of nests of epitheliod cell, with clear cytoplasm separated by delicate stroma (zellballen pattern).

\subsection{Case 2}

A 58-year-old male was admitted with a mass in the angle of the right jaw of 2 years duration. Ultrasonographic examination showed that there was a $5 \mathrm{~cm} \times 3 \mathrm{~cm}$ mass, without thrill or bruit. He was neither hypertensive nor diabetic, and did not have any family history of PGL. MR imaging showed a $63 \mathrm{~mm} \times 47 \mathrm{~mm} \times 24 \mathrm{~mm}$ hyperintense and capsulated mass encasing the common carotid artery (Figure 3). A preoperative angiogram demonstrated that vascularity of the tumor and tumor blush over the carotid bifurcation. Urinary MNs, VMA and I-MIBG scintigraphy were normal. He underwent surgery after alpha blocker agent. In the surgery, the tumour was juxtapositioned to the right external and common carotid artery. After careful attention, the tumour was totally excised without any complication. Histologically, the tumor was composed of organoid clusters of round cells with eosinophilic granular cytoplas. Additionally, the round chief cells with few cytoplasmic neurosecretory granules and spindle-shaped sustentacular cells were seen.

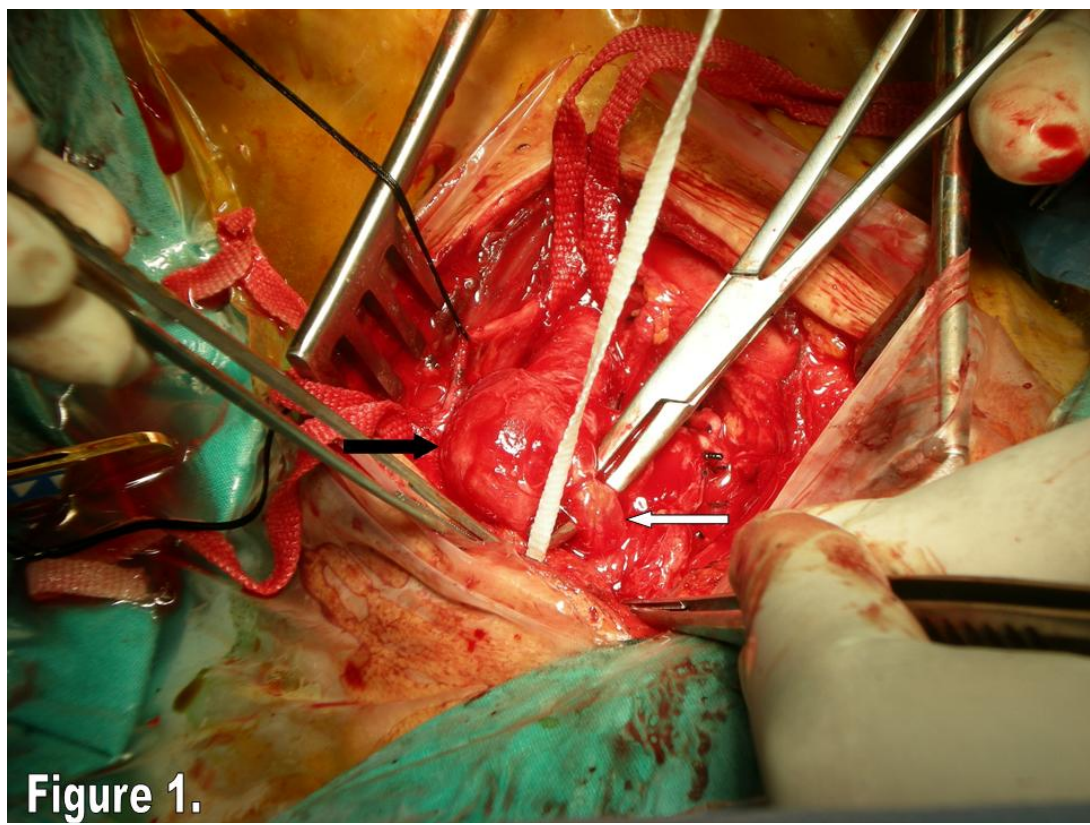

Figure 1. The carotid mass originating from carotid body (black arrow). The white arrowhead is demonstrating the external carotid artery. 


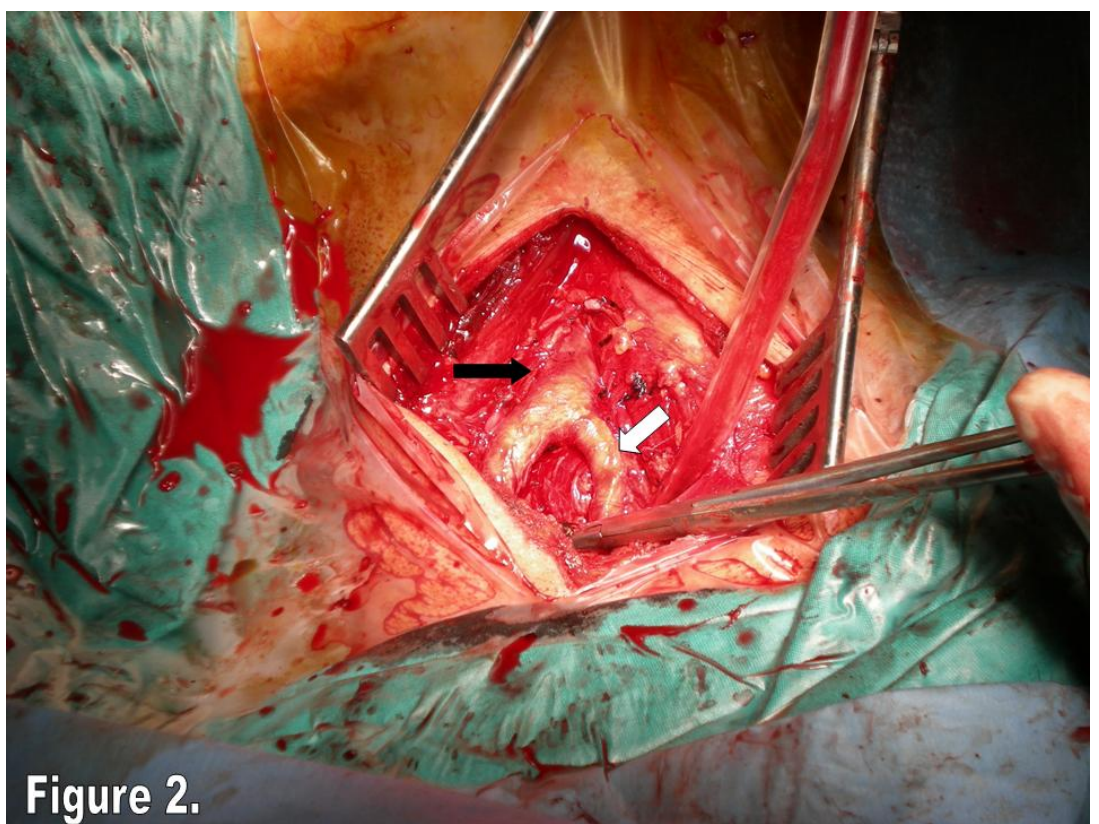

Figure 2. The appearance of surgical area after the excision of the carotid body mass.

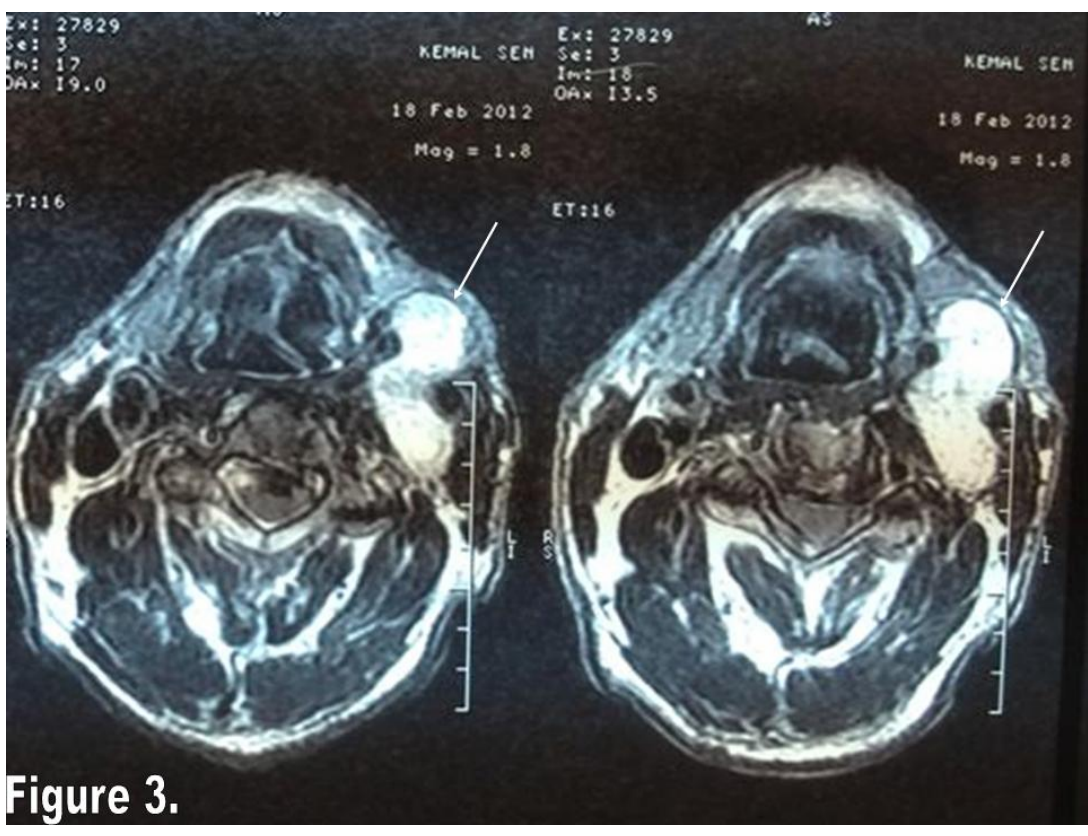

Figure 3. Magnetic resonance imaging shows that hyperintense and capsulated mass encasing the common carotid artery.

\section{Discussion}

Phaeochromocytomas are extra-adrenally located in 10\% of cases. $90 \%$ of these extra-adrenal PGLs are located in the abdomen. The remaining $10 \%$ of the extra-abdominal PGL a include CBT and glomus tumours [2]. The carotid body is a vascular reddish-brown structure about the size of a grain of rice located within adventitia posteromedial to bifurcation of the common carotid artery. The carotid body acts as a chemoreceptor responding to variations in oxygen tension and carbon dioxide concentrations; henceforth alternatively named chemodectomas [4]. There is an increased incidence in high-altitude dwellers and females [5]. The incidence of bilateral CBT varies from $10 \%$ to $25 \%$ in different series. We investigated bilateral CBT in our two cases, but CBT was 
only unilateral position in both patients.

The treatment of choice for paragangliomas is surgical excision [6]-[10]. Mataraci et al. reported their 9 patients who underwent surgical treatments [10]. According to description of Shamblin, these authors have described the surgical approach of carotid artery during the operations [10].

Because these are close to the important vessels and nerves there is risk of morbidity and mortality (3\% - 9\%). The risk seems to be significant when the tumor size is more than $5 \mathrm{~cm}(67 \%$ in $>5 \mathrm{~cm}$ and $15 \%$ when $<5 \mathrm{~cm})$. Shamblin developed a classification system for the carotid body tumors in 1971 [11]. Group 1 tumors are those which can be easily dissected from the adjacent vessels, group II tumors include those which are moderate in size adherent but separable from the adjacent vessels with careful dissection, and grade III tumors are usually large and engulf the carotid vessels necessitating partial or complete resection and replacement of the carotid vessels. A complete preoperative evaluation is necessary for safe resection of the tumor and reconstruction of the artery [12]. Preoperative embolization is going to reduce blood supply to the tumor but it may elicit inflammatory response in the tumor and some feel that it can make the subadventitial plane dissection more difficult [11]. Wide exposure is helpful in achieving the adequate hemostasis.

Patients with CBT typically present with a painless mass in the angle of the jaw which covered by the sternocleidomastoid muscle. At the time of diagnosis, cranial nerve palsies are present in $10 \%$ of cases with the X, XII, V and VII cranial nerves commonly involved in decreasing order of frequency [13] [14]. Carotid sinus syndrome with bradycardia, hypotension and unconsciousness can occur spontaneously. Episodic symptoms of phaeochromocytoma are seen in $1 \%-3 \%$ of cases. Noradrenaline is the main product and hypertension is the most frequent finding like our first case.

Initial imaging consists of MR imaging with contrast administration, with PGL showing an intermediate signal on T1-weighted images and a high signal on T2-weighted images. Total body scintigraphy using I-MIBG is also used as a screening tool to detect distant additional primary or metastatic lesion.

The success in treating benign and malignant PGL is based on early diagnosis, complete resection of the tumour after an adequate catecholamine blockade, which is given prophylactically. Complete resection of the primary mass is the treatment of choice. Postoperative cranial nerve deficits and arterial injury have remained a significant problem. Patients with larger tumours have an increased incidence of complications.

\section{Conclusion}

In conclusion, we continued an alpha blocker, additional fluid and a beta-blocker as a medication prior to surgery, and we stopped the treatment after surgical intervention. We have reported two cases of carotid body tumour and varying symptoms. CBT is a rare neoplasm. Its special anatomical position imposes great difficulty during surgery. Surgical planning and prediction of perioperative complications may be obtained by digital subtraction angiography, spiral CT angiography and color Doppler imaging. Arteriography, the gold standard for diagnosing CBPs, demonstrates a pathognomonic tumor blush as well as the feeding vessels of the tumor; and it is an excellent screening tool for concomitant paragangliomas. Adequate preoperative preparation and embolization of feeding arteries could reduce operative blood loss, improve tumor excision and preserve the internal carotid artery flow.

\section{References}

[1] Schwartz, S.I., Shires, G.T., Spencer, F.C., et al. (1994) Principles of Surgery. 6th Edition, McGraw Hill, New York, 273.

[2] Casati, A., Ferri, M., Lucandri, G., Fornari, F. and Sciacca, V. (1999) Carotid Body Tumors. Apropos a Caseand a Review of the Literature. J Chirg, 20, 229-232.

[3] Razakaboay, M., Maillefert, J.F., Wendling, D., et al. (1999) Bone Metastases from a Paraganglioma. A Review of Five Cases. Rev Rhum Engl Ed, 66, 86-91.

[4] Lack, E.E., Cubilla, A.L. and Woodruff, J.M. (1979) Paragangliomas of the Head and Neck Region. A Pathologic Study of Tumors from 71 Patients. Human Pathology, 10, 191-218. http://dx.doi.org/10.1016/S0046-8177(79)80008-8

[5] Zak, F.G. and Lawson, W. (1982) The Paraganglionic Chemoreceptor System. Springer, New York, 276-285. http://dx.doi.org/10.1007/978-1-4612-5668-7

[6] Lees, C.D., Levine, H.L., Beven, E.G. and Tucker, H.M. (1981) Tumors of the Carotid Body: Experience with 41 Operative Cases. American Journal of Surgery, 142, 362-365. http://dx.doi.org/10.1016/0002-9610(81)90349-4 
[7] Anand, V.K., Alemar, G.O. and Sanders, T.S. (1995) Management of the İnternal Carotid Artery during Carotid Body Tumor Surgery. The Laryngoscope, 105, 231-235. http://dx.doi.org/10.1288/00005537-199503000-00001

[8] Rutherford, R.B., Cottrell, E.D. and Smith, L.L. (1995) Management of Uncommon Lesions Affecting the Extracranial Vessels. In: Rutherford, R.B., Ed.,Vascular Surgery, W.B. Saunders, Philadelphia, 1623-1627.

[9] Muhm, M., Polterauer, P. and Gstottner, W. (1997) Diagnostic and Therapeutic Approaches to Carotid Body Tumors. Archives of Surgery, 132, 279-284. http://dx.doi.org/10.1001/archsurg.1997.01430270065013

[10] Mataraci, İ., Rabus, M.B., Kırali, K., Kiran, B., Yanartas, M., Sunar, H., Zeybek, R. and Yakut, C. (2008) Describtion and Treatment of Carotid Body Tumors. Turkish Journal of Thoracic and Cardiovascular Surgery, 16, 86-90.

[11] Shamblin, W.R., ReMine, W.H. and Sheps, S.G. (1971) Carotid Body Tumor (Chemodectoma): Clinicopathologic Analysis of Ninety Cases. The American Journal of Surgery, 122, 732. http://dx.doi.org/10.1016/0002-9610(71)90436-3

[12] Hallet Jr., J.W., Nora, J.D., Hollier, L.H., Cherry Jr., K.J. and Pairolero, P.C. (1988) Trends in Neurovascular Complications of Surgical Management for Carotid Body and Cervical Paragangliomas: A Fifty-Year Experience with 153 Tumors. Surgery, 7, 284-291.

[13] Westerband, A., Hunter, G.C. and Cintora, I. (1998) Current Trends in the Detection and Management of Carotid Body Tumors. Journal of Vascular Surgery, 28, 84-93. http://dx.doi.org/10.1016/S0741-5214(98)70203-4

[14] Ünlü, Y., Ates, A., Özyazicioglu, A., Becit, N., Erol, K., et al. (2001) Carotid Body Tumors (Paragangliomas). Asian Cardiovascular and Thoracic Annals, 9, 208-211. http://dx.doi.org/10.1177/021849230100900311 